\title{
Validity and Reliability Study of Parental Mediation for Internet Usage Scale Adolescent and Parent Forms in the Turkish Sample
}

\author{
Derya ATALAN ERGIN*
}

Emine Gül KAPÇI **

\begin{abstract}
Parental mediation includes parents' attitudes and behaviors about their child's media using. Early parental mediation researches have been conducted on television. Nowadays, parental mediation researches concentrate on the Internet. The main purpose of this study is to develop assessment forms that evaluate parental mediation strategies in respect of Internet Usage. In this study, a scale has been developed including parent and adolescent forms, as the strategies used by parents could be examined based on both parents and their children's self-report. A representative sample consisting of a total of 728 parents participated in the parent form study in Mamak, Ankara (mother $n=456$; father $n=272$ ). A total of 718 adolescents (female $n=371$; male $n=345$ ) aged 11 - 14 years old studying 6.-8. grades in a secondary school in Mamak participated in the adolescent form study. Exploratory factor analysis (EFA) and conformity factor analysis (CFA) were applied for the purpose of testing construct validity of the forms. EFA indicated that a two-factor model had enough fit for parent form and a three-factor model was suggested for adolescent form. Factors of parent form were named as "control/ restriction" and "active mediation", factors of adolescent form were named as "control/ restriction", "active mediation" and "monitoring". These factors have explained $63.7 \%$ and $61.7 \%$ variance on parent and adolescent scales, respectively. The results of CFA have revealed appropriateness of the factor structure (Parent form: $\chi^{2} / \mathrm{sd}=2.08$, RMSEA $=.06$, GFI: .91, AGFI: .88 , SRMR: .03, NFI: .98, NNFI:.99, CFI:.99; Adolescent form: $\chi^{2} / \mathrm{sd}=2.94$, RMSEA $=.07$, GFI: .88 , AGFI: .84, SRMR: .04, NFI: .98, NNFI:.98, CFI:.99). Assessed with Cronbach Alfa internal consistency reliabilities were calculated as .95 for both parent and adolescent forms. Test-retest reliabilities were .87 and .82 for parent and adolescent forms, respectively. These results have pointed out that both forms have the value of use in research on the evaluation of parental mediation on the Internet usage.
\end{abstract}

Key Words: Parental mediation, parent, adolescence, scale development.

\section{INTRODUCTION}

Nowadays, the Internet is among the most used media tools in terms of the opportunities that provides to build social networking and get information easily and quickly as well as the increase in the quantity of the information. The latest research results of TUIK (2018) in Turkey indicates that the access on the Internet at residences is $83.8 \%$. In the same research, the rate of being regular Internet user rates are 97.3\% for women and $97.6 \%$ for men. The age group that used The Internet more than the others in the last three months is between 16-24 (90.7\%). The data obtained from the abroad literature shows that adolescents use the Internet more than the other age groups (Treuer, Fabian \& Füredi, 2001; Widyanto \& McMurran, 2004).

In studies conducted with different cultures and age groups, it is pointed out that the usage of the Internet has increased and it provides opportunities to support the adolescents' both academic and social capability developments (Lenhart, Simon \& Graziano, 2001). However, the Internet also contains the risks such as accessing pornography (Sabina, Wolak \& Finkelhor, 2008), exposing to exploitation

\footnotetext{
* Dr, Ministry of Education, Ankara-Turkey, deryaatalan@gmail.com, ORCID ID:0000-0002-6602-1985

** Prof.Dr., Ankara University, Eğitim Bilimleri Fakültesi, Ankara-Turkey, eminegulkapci@ gmail.com, ORCID ID: 00000002-5094-9244
}

To cite this article:

Atalan Ergin, D., \& Kapçı, E., G. (2019). Validity and reliability study of parental mediation strategies for internet usage scale-adolescent and parent forms in the Turkish sample. Journal of Measurement and Evaluation in Education and Psychology, 10(2), 117-132. DOI: 10.21031/epod.457218. 
(Williams \& Merten, 2011) and Internet addiction (Spada, 2014). While forming and developing functional Internet usage habits, parents are the most important people to provide adolescents to benefit from the Internet and protect them from the risks. Variables such as parents` self-sufficiency perception regarding Internet usage (Glatz, Crowe \& Buchanan, 2018; Festl \& Langmeyer, 2018) and the features of Internet usage (Nikken \& Schols, 2015) affect the Internet usage of their children. Besides, parental mediation strategies in Internet usage (Fikkers, Piotrowski \& Valkenburg, 2017) that is especially discussed in studies made abroad seems to be related to the adolescents purpose and time of Internet usage.

Parental mediation strategies are defined as all the attitudes and behaviors of parents` who would like to increase the opportunities that children and adolescents meet in media as well as to decrease the risks of the Internet (Kirwil, 2009; Nathanson, 1999; Warren, 2001). The concepts of parental mediation or parental monitoring were first examined with the studies made for watching TV. With the proliferation of Internet usage, the concept was started to be examined for Internet usage. Although parental mediation strategies are believed to change forms regarding the differences between TV and Internet usage in terms of the abilities of the user, the user`s effectiveness level while using the media instrument and the ability level that is needed, studies show that the parental mediation strategies for Internet usage have similarities with those determined for the TV. (Sonck, Nikken \& de Haan, 2013). Studies show that parents use three basic mediation strategies that are restrictive mediation, active mediation and monitoring (Valkenburg, Krcmar, Peeters \& Marseille, 1999). Active mediation refers to the process of discussing certain aspects of programs with children, either during or after viewing (Valkenburg, Krcmar, Peeters \& Marseille, 1999). In this mediation strategy, parents explain some surreal events or the characters ' good and bad sides. In restrictive mediation, parents set up rules to limit the time or to prevent them to watch a particular content. Making use of some technologies to restrict particular channels, programs and websites are among the methods for restriction. Monitoring is defined as to monitor the Internet activities of adolescents afterwards (Cabello-Hutt, Cabello \& Claro, 2017). The Internet example is parents` habits to check the children`s "history” of Internet usage.

The level and kind of mediation strategies in Internet usage applied by parents may vary regarding some features such as parents` communication with their children (Valkenburg, Piotrowski, Hermanns \& de Leeuw, 2013), time (Fikkers, Piotrowsk \& Valkenburg, 2017), consistency between parents (Mares, Stephenson, Martins \& Nathanson, 2018), parents` education level (Clark, 2011; Nikken \& Schols, 2015; Pasquier, Simões \& Kredens, 2012; Shin \& Huh, 2011), self-sufficiency perception of parents for Internet usage (Glatz, Crowe \& Buchanan, 2018; Festl \& Langmeyer, 2018), being a family of single parent or regular parents (Barkin, Richardson, Klinepeter, Finch \& Krcmar, 2006), parental behaviors and the characteristics of the child (Padilla-Walker, Coyne \& Fraser, 2012). Functional usage of parental mediation prevents Internet addiction and exposing to cyberbullying (Chang, Chiu, Miao, Chen, Lee, Chiang \& Pan, 2015), and attempting the risky behaviors in the Internet (Sin \& Kang, 2016) and it also decreases the time spent on the Internet (Cabello-Hutt, Cabello \& Claro, 2017; Gomez Harris, Barreiro, Isorna \& Rial, 2017; Shin \& Kang, 2016). Besides, active mediation increases meeting with the opportunities that the Internet provides and restrictive mediation decreases meeting the risks (Livingstone, Ólafsson, Helsper, Lupiáñez-Villanueva, Veltri \& Folkvord, 2017). Using restrictive and active mediation together is claimed to be the most effective method for the Internet (Valkenburg, Piotrowski, Hermanns \& de Leeuw, 2013). While the risks of the Internet could be restrictive for adolescents` psycho-social and academic development, it is important to take into consideration that the opportunities that the Internet provides could support their development. Therefore, using all means of mediation strategies together may increase the benefits of the Internet.

In adolescence, the level and form of parental mediation strategies change due to the need for independence and autonomy (Chen \& Chng, 2016). Parents of adolescents use less restrictive mediation than the parents who have young children (Davies \& Gentile, 2012) or they decrease the level of mediation strategies they used in this period. This condition is related to the idea of parents that is older children have more self-check than the younger children (Lee, 2013) and they are more talented to cope with the negative effects of the Internet (Wang, Bianchi \& Raley, 2005). Moreover, younger children spend more time at home compared to the adolescents and this provides parents to control the Internet 
usage of them more often. Studies show that younger children have less level of healthy Internet usage habits in comparison to adolescents (Davies \& Gentile, 2012) and they spend more time before the monitor. These findings indicate that parental mediation strategies are important in terms of organizing the adolescents` Internet usage (Vaterlaus, Beckert, Tulane \& Bird, 2014). This study also reflects the importance of evaluating mediation strategies in puberty for these reasons.

The findings of the cultural studies made regarding parental mediation highlight different mediation strategies. In a study conducted in Brazil, Cabello - Hutt, Cabello and Claro (2017) determine the parental mediation strategies as "active mediation", "co-using" and "restrictive mediation". A measurement tool developed by Lee and Kim (2017) for Korean adolescents is formed by subdimensions of "restrictive mediation", "active mediation", "co-using" and "no mediation". Livingstone, Ólafsson, Helsper, Lupiáñez-Villanueva, Veltri and Folkvord (2017) developed a measurement tool that depends on the self-statement of parents and data from eight European countries which are very different from those two measurement tools related to the adolescents` self-statement. The subdimensions obtained from the scale are determined as "active mediation for Internet usage", "child-initiated support", "active mediation of Internet safety", "technical controls", "parental monitoring" and "parental restriction". The divergence in sub-dimensions indicates that evaluations regarding culture may provide important information.

Another significant subject in measuring parental mediation strategies is that how far measurement tools related to parents` and adolescents`statements are compatible with each other as well as culture (Wang, Bianchi \& Raley, 2005). In studies, half of the adolescents declare that they have parental mediation in Internet usage while this rate increases in the statements of parents (Rideout, Foehr \& Roberts, 2010). Gentile, Nathanson, Rasmussen, Reimer and Walsh (2012) point out that adolescent statements may indicate real mediation level better as parents may remark more mediation for social admiration. However, it is also possible that adolescents would like to emphasize their autonomy so that they would remark the mediation strategies less. Thus, scales obtained from both adolescents and parents provide more appropriate information to reveal the real condition.

In Turkey, studies regarding parental mediation in Internet usage have been conducted by qualitative analysis (Kılınç, 2017; Sütçü, 2017). The only quantitative study that also included Turkish sample about parental mediation was conducted by Bayraktar (2017). The study of Bayraktar (2017) was conducted on the data related to the database of European Union Kids Online II Project and the risks experienced on the Internet between Turkish people living in Europe and Turkish people living in Turkey and the relation of those risks with parental mediation strategies were evaluated. The mediation strategies regarding Internet usage were examined in four dimensions that are active mediation, active mediation regarding Internet safety, restrictive mediation and parental monitoring. However, the measurement tool used in this study was not developed in Turkish sample. In Turkey, there is a measurement tool that aims to measure the close features of parental mediation strategies and to determine the parents`attitude in terms of internet usage. Internet Family Attitude Scale was developed by Eijden (2007) and was adapted to Turkish by Ayas and Horzum (2013). The scale has two subdimensions that are family control and family closeness. As a result of the assessment by cutoff scores, parents` attitude could be examined as laissez-failure, permissive, authoritative and authoritative. The scale was formed with reference to Baumrind`s (1991) parenting style model. In the scale, the attitude and behaviors of Internet usage are laissez-failure attitude that contains low family control and closeness, authoritative attitude that contains high family control and low family closeness, permissive attitude that contains low family control and high family closeness and authoritative control that contains high family control and closeness (Ayas \& Horzum, 2013). "I determine the Internet rules with my child" or "I talk to my child about what he/she does with the Internet" can be cited as the closeness subdimensions of the scale adapted by Ayas and Horzum (2013). "I monitor my child while he/she surfs on the net" or "I use software to block specific Internet sites" can be cited for control. Recommended assessment style in related scale is by assigning to the groups with cutoff scores. For instance, the parents' behaviors that get lower than three in control items and higher than five in closeness items, parents are assessed as permissive. When the measurement tools in abroad literature are examined regarding parental mediation strategies in Internet usage, the items in the scale adapted by Ayas and 
Horzum (2013) are discussed in sub-dimensions of active mediation, control and monitoring (Hutt \& Cabello, 2017; Lee \& Kim, 2017; Livingstone \& Olafsson, 2017). Assessing the measurement tools concerning mediation strategies is done from the total score which is different from Internet Family Attitude Scale. The Internet Family Attitude Scale adapted by Ayas and Horzum and the differences between the dimensions and forms of the evaluation of the scales for parental mediation strategies developed in the literature of the abroad studies are indicative of the differentiation in the theoretical foundations. In Internet Family Attitude Scale, based on Baumrind's classification, authoritative parental attitudes are the desired behaviors. However, all of the forms (control, active mediation, couse) in parental mediation strategies are assessed as positive strategies. Therefore, bringing in an instrument to literature that is related to the assessment of parental mediation strategies in Internet usage is significant. Besides, two forms are aimed to be developed by gathering data from two sources in order to take into consideration the differences in adolescents`and parents`statements.

The importance of protecting adolescents from the risks of the Internet and the awareness about doing studies in this issue gradually increases in Turkey. The Ministry of Education conducts various studies in education institutions about Internet addiction and functional usage of information and communication technologies. It seems both important and necessary to consider the cultural differences while determining the parental mediation strategies. The main purpose of this study is to develop two forms that would reveal possible cultural differences in assessing the parental mediation strategies and that is based on both adolescents`and parents`statements.

\section{METHOD}

The model of the research is survey model that aims to describe the existing situation. The purposive sampling method was used to select participants. Thus, a sample was determined regarding the previous theoretical information about the universe, its own information and the special purpose of the research (Fraenkel \& Wallen, 1993). In this study, the purposive sampling method is preferred because adolescents need a social media or an e-mail account to fill in the evaluation instruments.

\section{Working Group}

The study groups are named as study group 1 for Explanatory Factor Analysis (EFA), study group 2 for Confirmatory Factor Analysis (CFA) and study group 3 for Test-Retest. In study groups, adolescent form is indicated by the letter $\mathrm{A}$ and parent form is indicated by letter $\mathrm{P}$ to emphasize the difference between the adolescent forms and parent forms. For parent form EFA study group is named 1P, for CFA study group is named $2 \mathrm{P}$; and for the adolescent form EFA study group is named 1A, for CFA study group is named $2 \mathrm{~A}$; for Test-Retest adolescent study group is named $3 \mathrm{~A}$, for parents' study group is named 3P. In the next parts, study groups will be referred with those names.

In the study, adolescents between the ages 11-14, having their secondary education in Ankara province, Mamak district and parents` whose children are at the same age range at the same school were contacted. For study group 1P 432 parents $\left(\mathrm{n}_{\text {mother }}=272, \mathrm{n}_{\text {father }}=160\right.$ ), and for study group 1A 361 adolescents ( $\mathrm{n}$ 6 th grade $=159, \mathrm{n}_{7 \text { th grade }} 115, \mathrm{n}$ 8th grade $=81$ ) were contacted. In study group $1 \mathrm{P}, 29.17 \%$ of them are primary school graduate $(n=126), 28.24 \%$ of them are secondary school graduate $(n=122), \% 33.79$ of them are high school graduate $(\mathrm{n}=146)$ and $\% 8.80$ of them are university graduate $(\mathrm{n}=38)$. For study group $2 \mathrm{P}$ 296 parents $\left(\mathrm{n}_{\text {mother }}=184, \mathrm{n}_{\text {father }}=112\right)$ and for the study group 2A 355 adolescents $\left(\mathrm{n}\right.$ 6th grade $=124,{ }_{n} 7$ th grade $=147, \mathrm{n}$ 8th grade $=84)$ were contacted. In study group $2 \mathrm{P}, 29.39 \%$ of the parents are primary school graduate $(n=87), 31.08 \%$ of them are secondary school graduate $(n=92), 30.07 \%$ of them are high school graduate $(n=89)$ and $\% 9.46$ of them are university graduate $(n=28)$. The study group 3 was formed from the randomly chosen and volunteered people in study group 1 and 2 that are 49 parents $\left(n_{\text {mother }}=34\right.$; $\left.\mathrm{n}_{\text {father }}=15\right)$ and 51 adolescents $\left(\mathrm{n}_{\text {girls }}=29 ; \mathrm{n}_{\text {boys }}=22\right)$ to calculate the reliability of the test-retest method. 


\section{Data Collection Instruments}

\section{Parental mediation for Internet usage scale - adolescent form (PMS-A)}

In order to measure the theoretical basis and parental mediation strategies, a pool of 54 items, each of which was evaluated in 5-point Likert type, was prepared considering the scales previously developed in abroad literature studies. When preparing the item pool, two sentences considered to measure the same feature were written. After the preparation of the item pool, opinions were received from five adolescents for the comprehension of the items through individual interviews and the items which were more understandable than the two items were taken into the measurement tool and the others were excluded from the measurement tool. After the arrangements, 25 items were remained and an "Expert Opinion Form" was prepared to assess the appropriateness and comprehensibility of the items by the experts. In the form that aims to have experts`opinion with 3-point Likert type, there is a part in which experts would point out their opinion and correction points for each item. The form was reached out by a specialist clinic psychologist, a psychological counsellor and guidance specialist, two academicians of education psychology, a Turkish language specialist and an evaluation and assessment specialist. With specialists suggestions, the measurement tool was determined to have 22 items. After the preapplication of the scale, the scale had the last arrangements before the main application.

\section{Parental mediation for Internet usage scale- parent form $(P M S-P)$}

In order to measure the theoretical basis and parental mediation strategies, a pool of 54 items, each of which was evaluated in 5-point Likert type and was formed of pairs, was prepared considering the scales previously developed in abroad literature studies. When preparing the item pool, two sentences considered to measure the same feature were written. After preparing the item pool, the assessment of comprehensibility for the items was done by three mothers and two fathers by individual interviews. One of the two items that measure the same feature was taken into the measurement tool and the other one was excluded. After the arrangements done on the items by parents` evaluations, in order to assess the appropriateness and comprehensibility of 25 items, an "Expert Opinion Form" was sent to a specialist clinic psychologist, a psychological counsellor and guidance specialist, two academicians of education psychology, a Turkish language specialist and an evaluation and assessment specialist. With specialists` suggestions, the scale had 23 items and pre-applications were done for the main application.

\section{Personal information form}

In addition to the adolescents` scale, the form regarding information about a nickname, gender, grade or whether having an e-mail or social media account or not was given to the participants. For parent form, the participant of each parent was given a form regarding the information about a nickname, closeness degree (mother or father), education level, having knowledge about whether his/her child has an e-mail or a social media account or not. Information about e-mail and social media account are necessary to answer the questions about the related accounts in the measurement tool. Participants who don't have any e-mail or social media account were excluded from the study.

\section{Data Collection Procedure}

Before the data collection, legal permission regarding the application was obtained from the Ministry of Education. Afterwards, the appropriate days and hours of practice for the institution and the grades of the study group were determined. The parents of study group students were sent "Informed Consent Form" one week before the application. Related form contains the purpose of the research, by whom it is going to be done, the duration of time to fill in the scales, privacy policy, the communication information of the researcher, and consent parts. In this stage, the parents of all 6th, 7th and 8th-grade students were given PMS- P by the students (who have a social media and an e-mail account). This process was carried out one week before the application to be made to the adolescents by considering 
that the return period of the forms would be completed by the parents. As a result, a total of 987 parents were sent the forms and 728 returns were provided. No data loss was experienced by the data returned and the return rate was stated as $73.75 \%$. After the expected week for the return of the consent forms, adolescents had the application. The participants of each class level who had parental consent form were met in an empty class arranged by the school administration. Before collecting the data, the participants were informed about the purpose of the study, privacy and volunteering policy. Next, they were asked whether they have an e-mail and a social media account which is necessary to participate in the research. Students who have not at least one of the related accounts were excluded from the study. After this process, the participants filled the measurement tool and personal information form. There was no one who did not want to participate in the study or who left the form undone. Applications lasted about 20 minutes. After four weeks of all the applications were done, responses of randomly and voluntarily selected parents and adolescents were used to calculate the test-retest reliability.

\section{Data Analysis}

While developing PMS-A and PMS-P forms in the study, Principal Component Analysis was used to present the factor design of the forms as the factorization method. In this study, it was investigated whether there is a similarity between the structure of the theory that helps the behavior to be understood with EFA and factors or not. Next, CFA was done to test the structural validity of the forms. In order to overcome the missing data problem to prepare the data sets for the analysis, the median replacement was preferred since it was suggested that all possible strategies for ..... missing data would have similar results (Tabachnick \& Fidell, 2001) the data was collected by ordinal type of scale (Hastie, Tibshirani, Sherlock, Eisen, Brown \& Botsein, 1999).

\section{RESULTS}

Principal Component Analysis was chosen for the factorization method for PMS-A and PMS-P and oblique method was chosen as direct oblimin method.

For both of the forms, the data set before the EFA and CFA were checked in terms of size of the sample, missing data, multivariate and univariate normality, linearity, multivariate and univariate outliers analysis, multicollinearity and singularity. For both of the forms, findings obtained from the hypothesis tests done before the EFA and CFA were given. After determining that the hypothesis was met, the EFA process started for the forms. For both of the forms, eigenvalue greater than 1, scree plot, the contribution of factors to the variance and the results of Horn`s Parallel Analysis were assessed altogether while determining the factor numbers. From the items that are cyclical or the factor load value of which are under .32 (Tabachnick \& Fidell, 2001); first the cyclical ones and later those the factor load value of which is .32 were removed from the scale.

\section{Testing Assumptions for EFA in PMS-A Data Set}

While testing the structure validity in the study group -1A for EFA, 361 adolescents were contacted. Whether the sample size is adequate for EFA was tested by Kaiser-Meyer-Olkin statistics and the value was found .95 for PMS-A that was sufficient for the process. While checking missing data, there was no parameter of missing data rate over $\% 5$ and parameters under $\% 5$ was done median designation. Multivariate normality was assessed by Bartlett Globality Test and the multivariate normality for PMS A was met $\left(\chi^{2}(231)=4937.986 ; p<.05\right)$. Univariate normality was examined by Levene Test and significance level seemed to be met the present assumption since it was bigger than $.05\left(\mathrm{LF}_{(2,358)}=.754\right.$, p>.05). Linearity was checked by the scatter diagram and the elliptical shape of the diagram also met that assumption. For multicollinearity VIF, case index (CI) and tolerance value were checked while for the singularity problem the correlation coefficient between pairs of items were checked. Accordingly, VIF value is smaller than $10, \mathrm{CI}$ is smaller than 30 and tolerance value is bigger than .10 that indicates there is not any multicollinearity problems (Çokluk, Şekercioğlu \& Büyüköztürk, 2014). Singularity is 
the state of correlation coefficient being $\mathrm{rxy}=1.00$ between the item pairs (Şencan, 2005). Accordingly, in PMS-A (VIF=1.000, CI=1.000 and tolerance rate $=1.000$; the correlation coefficient between the pairs of the item is .24-.71) there is no multicollinearity or singularity problem. In multivariate and univariate outlier analyses assessed by Mahalonobis Distance and $\mathrm{Z}$ points, there were no outliers.

\section{EFA Process Steps for PMS-A}

As a result of the analysis for the 22 items based on EFA in PMS-A, it is appropriate to assess the scale by the three-factor structure. Two items were excluded from the analysis in items examination. In consequence of EFA of 20 items, three subscales are labeled as 'control/restriction', 'monitoring' and active mediation`. The contribution of the factors on the total variance is $27.08 \%$ for ‘control/restriction`, $18.86 \%$ for 'active mediation` and $15.80 \%$ for `monitoring'. The total contribution of those three factors on the variance is $61.74 \%$. Factor loading for each factor are presented in Table 1.

Table 1. Factor Load and Common Factor Variance for PMS-A

\begin{tabular}{|c|c|c|c|}
\hline Items & $\begin{array}{l}\text { 1. factor } \\
\text { (Control/ } \\
\text { restriction) }\end{array}$ & $\begin{array}{l}\text { 2. factor } \\
\text { (active } \\
\text { mediation) }\end{array}$ & $\begin{array}{l}\text { 3. factor } \\
\text { (monitoring) }\end{array}$ \\
\hline He/She monitors the games I play on the Internet. & .79 & .15 & .03 \\
\hline $\begin{array}{l}\text { My family determines a rule about turning off a device that I can access the } \\
\text { Internet (such as phone, computer) on a definite time. }\end{array}$ & .82 & .02 & .16 \\
\hline He/She checks what I do on the Internet. & .85 & .02 & .09 \\
\hline He/She checks my correspondence on social networking sites. & .66 & .04 & .19 \\
\hline He/She takes precautions to prevent my access to unsafe Internet websites. & .55 & .20 & .04 \\
\hline He/She checks the Internet websites I visited. & .66 & .05 & .17 \\
\hline He/She checks what I shared on social networking sites. & .59 & .06 & .18 \\
\hline He/She limits the time that I use on the Internet. & .65 & .07 & .05 \\
\hline He/She checks the people I texted on my mobile phone. & .62 & .03 & .24 \\
\hline He/She checks whether I made a video chat with strangers or not. & .57 & .17 & .08 \\
\hline $\begin{array}{l}\text { He/She monitors whether I exceed the time that I suppose to spend on the } \\
\text { Internet or not. }\end{array}$ & .53 & .27 & .09 \\
\hline He/She encourages me to use the Internet to get information. & .06 & .84 & .06 \\
\hline $\begin{array}{l}\text { He/She encourages me to use the Internet to do my homework or to support } \\
\text { my lessons. }\end{array}$ & .09 & .86 & .04 \\
\hline $\begin{array}{l}\text { He/She encourages me to share the new information I learnt from the Internet } \\
\text { with him/her. }\end{array}$ & .06 & .73 & .05 \\
\hline $\begin{array}{l}\text { He/She listens to me when I share the new information I learnt from the } \\
\text { Internet with him/her. }\end{array}$ & .02 & .70 & .14 \\
\hline He/She talks about the negativeness of writing people that I don`t know. & .19 & .60 & .07 \\
\hline $\begin{array}{l}\text { He/She asks me to tell or show my personal information to him/her before I } \\
\text { share them on the Internet. }\end{array}$ & .19 & .30 & .47 \\
\hline He/She knows my passwords for social networking sites. & .05 & .06 & .89 \\
\hline He/She checks my e-mail correspondences. & .37 & .06 & .63 \\
\hline He/She knows my e-mail password. & .33 & .01 & .85 \\
\hline
\end{tabular}

\section{Testing Assumptions for CFA in PMS-A Data Set}

Similar to EFA, in CFA process which is made to confirm the structures resulted from the EFA for PMS-A, first of all, assumptions were tested. The assumptions in the data set of 355 participants for PMS-A were tested. The results of the Kaiser-Meyer-Olkin statistics were .96 for PMS-A and that proved to be reached out the sufficient sample size. While checking missing data, there was no parameter of missing data rate over $\% 5$ and parameters under $\% 5$ was done median designation. The results of 
Barlett Globality Test met the multivariate normality in PMS-A $\left(\chi_{(190)}^{2}=4954.237 ; \mathrm{p}<.05\right)$. The results of Levene Test indicated that the univariate normality was met $\left(\operatorname{LF}{ }_{(2,352)}=.317, \mathrm{p}>.05\right)$. The elliptical appearance of scatter diagram proved linearity. For multicollinearity, VIF, CI and tolerance values and for singularity problem, the correlation coefficient between pairs of items were checked. The assessments show that the assumptions for the multicollinearity and singularity were met $(\mathrm{VIF}=1.000$, $\mathrm{CI}=1.000$ and tolerance value $=1.000$ the correlation coefficient between the pairs of items is $.25-.72$ ). In multivariate outliers analysis, 12 data were excluded from the data set since they are above the critical chi-square value. However, there were no outliers based on univariate outlier analyses. After determining that all the assumptions were met for CFA, the analysis procedure was initiated.

\section{Steps of CFA Process for PMS-A}

In CFA, t values for each item are between 11.81 - 11.76 (Figure 1) and standardized analysis values are between .59 and .84 (Figure 2). Calculated t values for all the items are significant at $\mathrm{p}<.01$ level.
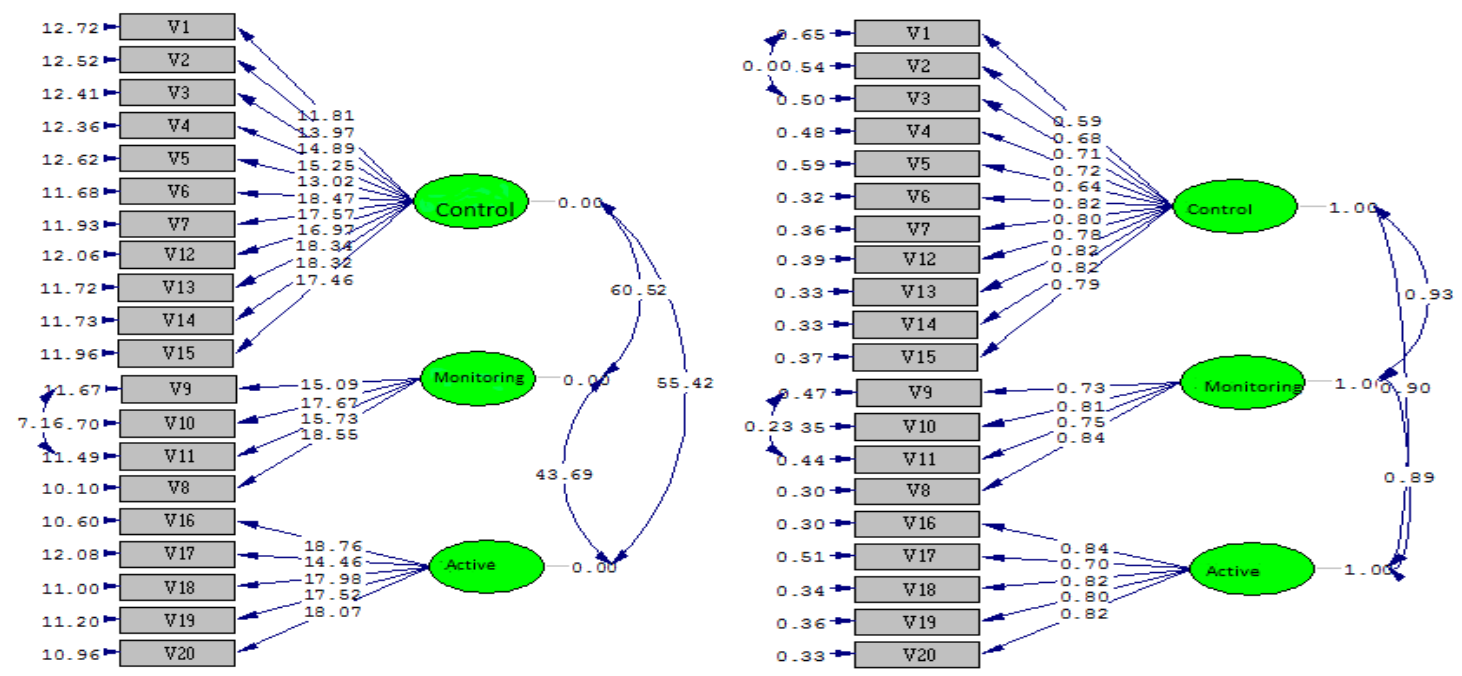

Figure 1. $t$ values of the Items

Figure 2. The standardized Factor Loadings of the Items

When the fit index resulting from CFA is examined, $p$-value of $\chi^{2}$ value is significant $(p<.05)$. This finding indicated that there was a significant difference between expected and monitored covariance matrix. Therefore, the $\chi^{2} / \mathrm{sd}$ ratio $(620.33 / 167)$ was calculated and the rate was 3.71 . In larger samples, even the p-value is significant, $\chi^{2} / \mathrm{sd}$ rate under 5 shows sufficient fit (Çokluk, Şekercioğlu \& Büyüköztürk, 2014). Regarding the examinations with other fit indexes showing that the RMSEA value was not at the desired level $(\mathrm{RMSEA}=.11)$ and the $\chi^{2} / \mathrm{sd}$ rate was close to 5 , modification suggestions were examined. Accordingly, some modifications were done with the items $11(\mathrm{He} / \mathrm{She}$ knows my email password) and 9 (He/She knows my social networking sites passwords) and with the items 1 (He/She monitors the games I play on the Internet) and 3(He/She checks what I do on the Internet) since they were under the same factor and have close meanings. In the modifications, when the corrections were added to the model for the errors between the items 11 and 9, the decreased in chi-square value was 77.9 and similarly, it was 41.7 between the items 1 and 3 . When the goodness fit values were checked in the model after the modifications, the $\chi^{2} /$ sd rate was 2.94 . This value showed a perfect fit in large samples (Sümer, 2000; Kline, 2005). However, finding the significance level $p<.05$ could be originated from the large sample (Çokluk, Şekercioğlu \& Büyüköztürk, 2014). Thus, the rate was proof of model data fit. When the goodness fit values of the model were checked, RMSEA indicated (.07) good fit (Hooper, Coughlan \& Mullen, 2008; Sümer, 2000). The GFI (.88) and AGFI (.84) values indicated acceptable fit, SRMR (.040) indicated perfect fit (Brown, 2006), NFI (.98) and NNFI (.98) indicated good fit (Tabachnick \& Fidell, 2001); and CFI (.99) also indicated perfect fit (Hu \& Bentler, 
1999; Sümer, 2000; Thompson, 2004). According to the CFA results, the three-factor model was acceptable.

The Cronbach Alfa reliability coefficient obtained from study group -2A for 20 items of the scale was found to be .95 . The Cronbach Alfa internal consistency coefficients of Control/Restrict, Active mediation and Monitoring were calculated as $.91, .79$, and .78 in order. This value indicated that the reliability of the scores obtained from the scale was high. In findings of study group 3A, the reliability coefficient of the scale regarding its test-retest reliability was .82 for the whole scale. The test-retest reliability coefficient of the control/restriction, active mediation and monitoring were $.89, .81$, and .78 , respectively.

\section{Testing the Assumptions for EFA in PMS-P Data Set}

For the study group -1P, 432 parents were contacted. Whether the sampling size was adequate for EFA was tested by Kaiser-Meyer-Olkin statistics and the value was found to be .97 and showed sufficient sample size was met for EFA in the data set. While checking missing data, there was no parameter of missing data rate over $\% 5$ and parameters under $\% 5$ was done median resignation. Multivariate normality was assessed by Barlett Globality Test and the multivariate normality was met $\left(\chi^{2}(630)=\right.$ 11052.844; $\mathrm{p}<.05)$. Univariate normality was examined by the Levene Test and significance level seemed to be met the present assumption since it was bigger than $.05\left(\operatorname{LF}_{(2,429)}=1.581, p>.05\right)$. Linearity was checked by scatter diagram and the elliptical shape of the diagram also met that assumption. For multicollinearity VIF, case index (CI) and tolerance value were checked while for the singularity problem the correlation coefficient between the pairs of the items were checked. Findings of the form showed that there was not any multicollinearity or singularity problem in PMS- P. (VIF=1.000, $\mathrm{CI}=1.000$, and tolerance rate $=1.000$; the correlation coefficient between the pairs of the items is .31 .84) In multivariate and univariate outlier analyses assessed by Mahalonobis Distance and $\mathrm{Z}$ points, there was no outliers.

\section{EFA Process Steps for PMS-P}

As a result of the assessments done to determine the factor numbers for the 23 items based on EFA in PMS-P, analysis continued with the two-factor structure of the scale. Five items were excluded from the scale after examining the items. In consequence of EFA of 18 items, factors were labeled as "control/restriction", and "active mediation". The contribution of the factors on the total variance was $32.46 \%$ for "control/restriction" and $25.28 \%$ for the "active mediation". The total contribution of those two factors on the variance was $63.74 \%$. The factor loadings for each factor are presented in Table 2 .

\section{Testing the Assumptions for CFA in PMS-P Data Set}

Similar to EFA, in CFA process which was made to confirm the structures resulted from the EFA for PMS-P, first of all, assumptions were tested. The assumptions were tested in the data set of 296 participants for study group -2P. The result of the Kaiser-Meyer-Olkin statistics was .96 for PMS-P and that proved to be reached out the sufficient sample size. In missing data control, 25 parameters the missing data rate of which was above $\% 5$ were excluded from the data set. Parameters under $\% 5$ were done median resignation. The results of Barlett Globality Test met the multivariate normality $\left(\chi_{(153)}^{2}=\right.$ $4293.491 ; \mathrm{p}<.05)$. The results of the Levene test indicated that the univariate normality was met $\left(\operatorname{LF}_{(2,293)}\right.$ $=.067, \mathrm{p}>.05)$. The elliptical appearance of the scatter diagram proved linearity. For multiple connectedness problem VIF, case index (CI) and tolerance value and for singularity problem, the correlation coefficient between the pairs of items was checked. The assessment showed that the assumptions for the multicollinearity and singularity were met. (VIF=1.000, $\mathrm{CI}=1.000$, and tolerance value $=1.000$.The correlation coefficient between the pairs of items was $.31-.87$. In multivariate outlier analyses, 12 data points were excluded from the data set since they were above the critical chi-square 
value. However, in univariate outlier analyses, there were no outliers. After determining that all the assumptions were met for CFA, analysis procedure was initiated.

Table 2. Factor Loads for PMS-P

\begin{tabular}{|c|c|c|}
\hline Items & $\begin{array}{l}\text { 1. factor } \\
\text { (Control/ } \\
\text { Restriction) }\end{array}$ & $\begin{array}{l}\text { 2. factor } \\
\text { (active } \\
\text { mediation) }\end{array}$ \\
\hline I check who he/she adds as a friend on social networking sites. & .78 & .28 \\
\hline I check his/her immediate text messages.. & .78 & .28 \\
\hline I know his/her passwords for the social networking site. & .75 & .13 \\
\hline I check his/ her e-mail correspondence. & .74 & .26 \\
\hline I check the applications he/she downloads. & .74 & .26 \\
\hline I check what he/she shares on social networking sites. & .71 & .40 \\
\hline $\begin{array}{l}\text { I ask him/her to tell or show me his/her personal information before he/she shares it on the } \\
\text { Internet. }\end{array}$ & .69 & .31 \\
\hline $\begin{array}{l}\text { If I see any inappropriate correspondence with his/her friend, I make sure that he/ she will } \\
\text { exclude that friend from his/her friend list. }\end{array}$ & .68 & .29 \\
\hline $\begin{array}{l}\text { I ask him/her to show me the photos or videos of our family, friends or his/her friends before } \\
\text { he/she uploads them. }\end{array}$ & .68 & .36 \\
\hline I check the websites that he/ she visits. & .68 & .40 \\
\hline While my child is online, I go next to him/her and watch him/her. & .67 & .44 \\
\hline I limit the time that he/she spends on the net. & .60 & .39 \\
\hline I use a filtration method to prevent him/her to access inappropriate content. & .59 & .32 \\
\hline I ask him/her to tell me anything that disturbs him/her in his/her Internet correspondence. & .34 & .84 \\
\hline I talk to my child about the negative aspects of texting to someone that he/she doesn`t know. & .38 & .81 \\
\hline I talk to my child about unsafe websites. & .37 & .78 \\
\hline If my child asks for my help about the Internet, I do my best to help him/her. & .18 & .78 \\
\hline I listen to my child when he/she shares the new information that he/she learnt from the Internet. & .32 & .77 \\
\hline
\end{tabular}

The standardized factor loadings of each item in PMS-P was between $.64-.91 . \mathrm{t}$ values that were assessed to determine whether the standardized analysis value was significant or not were between 12.02 and 19.71. Calculated $t$ values were significant at $p<.01$ level for all of the items. $t$ values are shown in Figure-3 and standardized loadings are shown in Figure-4.
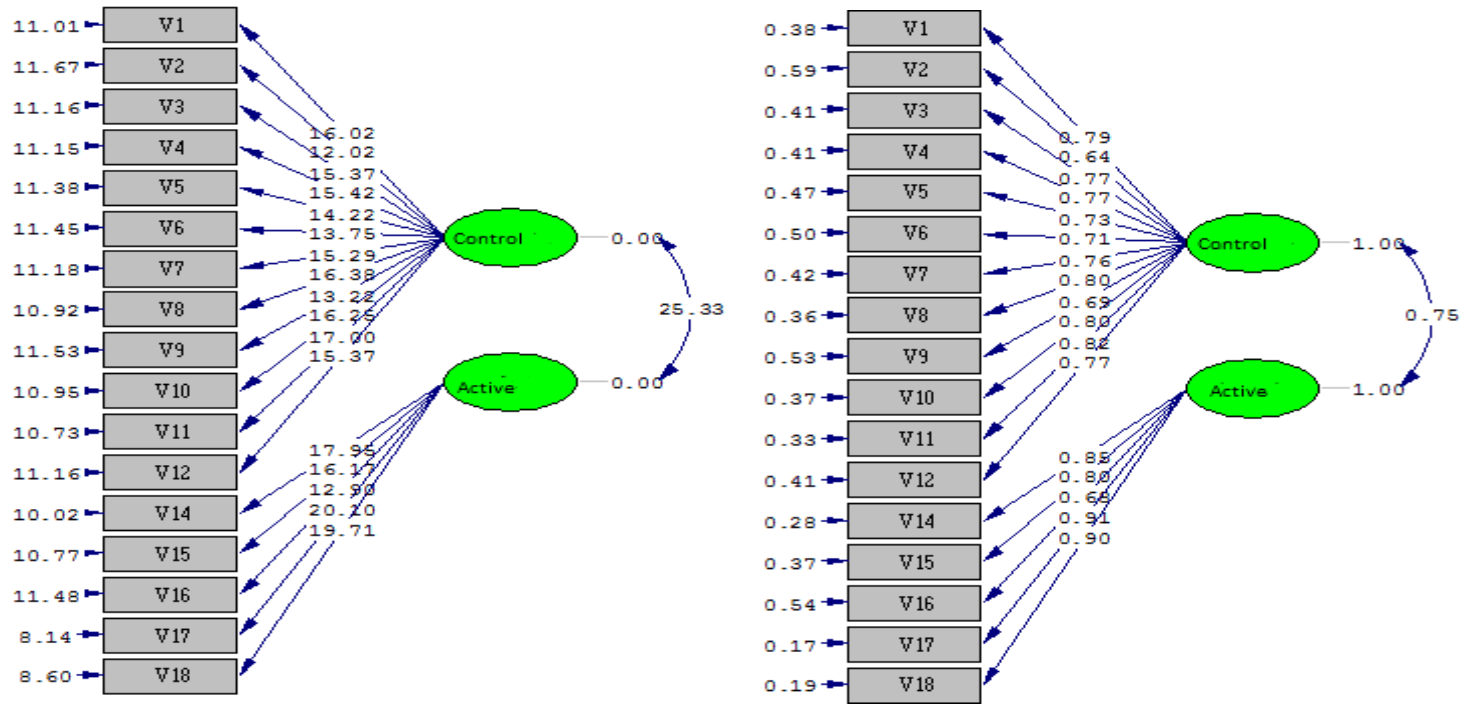

Figure 3. $t$ values of the items

Figure 4. Standardized Factor Loadingsof the Items 
When the fit indexes obtained from the results of the CFA were examined, $\chi^{2} / \mathrm{df}$ rate indicated (2.08) perfect fit (Sümer, 2000; Kline, 2005), RMSEA value (.06) indicated good fit (Hu \& Bentler, 1999; Thompson, 2004), GFI and AGFI values indicated $(.91, .88)$ good fit (Hooper, Coughlan \& Mullen, 2008; Sümer, 2000); SRMR value indicated (.03) perfect fit (Brown, 2006; Burne, 1994), NFI and NNFI values $(98, .99)$ also indicated perfect fit (Tabachnick and Fidell, 2001); CFI value (.99) indicated perfect fit ( Hu and Bentler, 1999, Sümer, 2000).

After finalizing the scale, the Cronbach Alfa reliability coefficient obtained from CFA study group of 18 items was calculated as .95 . The same coefficient was found as .95 for control/restriction subscale and .93 for active mediation subscale. This value showed the high internal consistency of the scale. In the findings obtained from the 3P study group, the reliability coefficient of test-retest of the scale was calculated .87 for the whole scale. The reliability coefficients of the test-retest in the control/restriction and active mediation subscales were .89 and .86 , respectively.

Finally, the structures obtained by EFA for PMS-A and PMS-P were confirmed by CFA. Both of the scales can be stated as the appropriate measurement tools for Turkish culture to evaluate the parental mediation strategies in Internet usage for adolescents between the ages of 10 and 14 .

\section{DISCUSSION and CONCLUSION}

In this study, it was aimed to develop two forms regarding the statements of adolescents and parents to assess the parental mediation strategies in Internet usage of adolescents. First of all, item pools were formed for both of the forms. While forming the item pools, the measurement tools from international studies in this field and the theoretical base of the topic were considered and two items that were supposed to evaluate the same features were written. In these item pools, the statements of five adolescents for the adolescent form and the statement of five parents for the parent form were applied. The item which was stated to be more comprehensible than the two items written in accordance with the opinions received by individual interviews with both parents and adolescents was included in the measurement tool. Thus, there were 25 items each in adolescents and parent forms. Then, an expert opinion form in 3 points Likert type that aims to assess the items in terms of appropriateness and comprehensibility was given to a specialist clinical psychologist, a psychological consultant and guidance specialist, two academicians in the field of psychology of education, a Turkish language specialist and a measurement and evaluation specialist. Regarding the experts' suggestions, the adolescent form was formed of 22 items and the parent form was formed of 23 items. The items were finalized by the pre-application and then the main application started. The validity of the structure for both of the scales done by EFA for PMS-A and PMS-P was proved. After the items were examined in terms of cross-loadings and magnitude of the factor loading, PMS-A was formed of 20 items while PMS-P was formed of 18. In the three-dimensional structure of the PMS-A, the variance was found to be $61.74 \%$ and in the two-factor structure of the PMS-P, the variance was found to be $63.74 \%$. For social sciences, the explained variance between $40 \%$ and $\% 60 \%$ is sufficient (Scherer, Wiebe, Luther and Adams, 1988). The explained variance for both of the developed forms is at a good level. When the factor loading values obtained from the measurement tools were examined in terms of magnitude, it is possible to describe it from "good" to "perfect" (Comrey \& Lee, 2013). In PMS-A form, the subdimensions were called as "control/restriction", "active mediation" and "monitoring". However, there was no monitoring subscale in PMS-P and subdimensions were called as "control/restriction" and "active mediation".

In CFA for adolescent form, the RMSEA value was not at the desired level and therefore the model fit indexes suggested by the package program were examined. After the parameter predictions and indexes are examined, the researchers could make modifications to the model to have a better fit or more complex model (Schreiber, Nora, Stage, Barlow \& King, 2006) and those modifications should match up with the theoretical structure (Diamantopoulos \& Siguaw, 2000). Thus, two modifications were made in adolescent form and in this way RMSEA values seemed in acceptance boundary. For parent form, no modifications were done and the first structure was supported by the CFA. Finally, In CFA both for adolescents and parents, model fit indexes were at acceptance boundary. In assessments for reliability, 
the internal consistency coefficient indicates that the form has high reliability and the results of testretest show that forms have high stability.

Parental mediation strategies for Internet usage may be defined as the concept that expresses the attitudes and behaviors of parents about their children`s Internet usage. There are studies that show that both quality and quantity of mediation strategies used by parents in adolescence are different from those in childhood (Davies \& Gentile, 2012; Gentile, Nathanson, Rasmussen, Reimer \& Walsh, 2012). For instance, "restrictive mediation" is used less by parents in adolescence (Davies \& Gentile, 2012). Because of the findings that show the quality and quantity of parental mediation strategies have changed, in this study it was aimed to develop a measurement tool especially for the individuals in adolescence.

When the parental mediation strategies are evaluated, it is important to consider the differences between the statements of adolescents and parents. Studies in recent years have expressed that parents tend to do higher mediation than adolescents (Rideout, Foehr \& Roberts, 2010). This condition is related to the one in which parents declare higher mediation to obtain social appreciation so it is stated that the result of the adolescents`statements would be more realistic (Gentile, Nathanson, Rasmussen, Reimer \& Walsh, 2012). However, adolescence is a period in which autonomy develops and independence from parents begins. When it is assessed through this point of view, adolescents would like to state a high autonomy level so it may cause a low level of parental mediation strategies results. Thus, the forms in this study developed according to the statements of both parents and adolescents.

The early studies regarding parental mediation strategies have been conducted on television. In the theoretical base of the concept, mediation strategies that were active mediation, control/restriction, monitoring and co-use were defined. There is a similar structure in studies of mediation strategies for internet usage with the mediation strategies used for watching television (Sonck, Nikken \& de Haan, 2013). The basic differences between the dimensions of the mediation strategies used in television and used in Internet usage are detected in co-use and technical restrictions. In studies of Sonck, Nikken and de Haan (2013), co-use was not determined as a dimension and this condition was attributed to that Internet usage has a more individual activity unlike, television usage. Technical restrictor mediation, different from the television, is among the mediation strategies for Internet usage. For instance, in a study made by Livingstone (2017), technical control is determined as a dimension. The dimension that contains the items mostly about software regulation is considered sensible not to be discussed in researches of parental mediation strategies in television usage. One of the studies regarding parental mediation strategies in internet usage was conducted in Brazil and three dimensions that are "active mediation", "co-using" and "restrictive mediation" were determined (Cabello-Hutt, Cabello \& Claro, 2017). The data obtained from eight European countries revealed the dimensions of "active mediation for Internet usage", "child-initiated support", "active mediation of Internet safety", "technical controls", "parental monitoring" and "parental restriction" (Livingstone et al., 2017). Unlike those cultures studied, parental mediation strategies were assessed with dimensions of "restrictive mediation", "active mediation", "co-using" and "no mediation" in a study made in Korea (Lee \& Kim, 2017). In Turkey, however, no instruments were observed in terms of evaluating parental mediation strategies. In the two forms developed in this study, the dimensions of "active mediation", "monitoring" and "control/restriction" were determined since they were the most determined dimensions in studies made in different cultures. While forming the item tool, the scales that were developed before in abroad literature studies to measure the theoretical base and parental mediation strategies were grounded on. In those scales, the most discussed items were assessed and it was aimed to prepare items that would include all kinds of socio-economic levels of parents and adolescents regardless of digital skills. Finally, those three sub-dimensions are considered to support the structure of the two forms developed for the study.

A tool that was developed by Eijden (2007) to measure the parents' attitudes in Internet usage was adapted to Turkish by Ayas and Horzum (2013). The theoretical base of that tool is based on the parenting style model of Baumrind (1991). The attitudes and behaviours of parents are assessed in quartet structure formed according to the different levels of control and proximity dimensions. These structures are called permissive, laissez-failure, authoritarian and authoritative. The authoritative attitude that is expressed by high parents control and closeness contains desirable attitudes and 
behaviours. In assessments of items base, the items discussed in terms of closeness and control dimensions in Parental Attitude Scale are addressed in different sub-dimensions in PMS. The differences in the theoretical base affect the formation of dimensions in measurement tools. Internet Family Attitude Scale differs from the PMS in terms of its assessment criteria. In Internet Family Attitude Scale, an assessment can be done regarding the total points in closeness and control dimensions or the results can be examined according to the quartet structure. The parents' behaviours that get points lower than 3 in control items and higher than 5 in closeness items are evaluated as permissive. Authors declare that this evaluation type is the one that is used in the original form of the scale. However, the applications in all those items that are discussed under different dimensions in PMS indicate the increase in the level of parental mediation strategies and that is interpreted as a desirable condition. Finally, since there is not a measurement tool developed in the theoretical base of parental mediation strategies in Turkish Literature, it has revealed the necessity to develop a measurement tool that contains the self-report of both parents and adolescents for that purpose.

In this study, two forms were developed in terms of the self-reports of adolescents and parents. In PMSA form, three-dimensional structures of "control/restrict", "active mediation" and "monitoring" appeared and in PMS-P form two-dimensional structures of "control/restrict" and "active mediation" were confirmed. Some of the items in adolescent form in monitoring sub-dimensions ("He/She knows the passwords of my social networking site", "He/She asks me to show him/her my personal information before I share them on the net.") take part in the control/restrict sub-dimension in parent form. This situation indicates that the behaviors of parents for Internet usage were perceived differently by parents and adolescents. Adolescence is a period in which egocentric thoughts dominate (Steinberg, 2007). "Imaginary audience" is one of the basic concepts for this thought. According to that, the adolescence thinks that everyone around him/her watches him/her and all the attention are on him/her all the time (Elkind, 1974). Therefore, the parents' knowledge of their passwords of the social networking sites may be perceived as they are being monitored and followed for adolescents while just having the password is a control/restrict method for parents. The items in control/restrict sub-dimension in parent form taking part in monitoring in adolescent form indicates a structure formed as a result of the egocentric way of thinking in adolescents.

In this study, two forms were developed for the adolescents between the ages 11-14 (6th-8th grade) and their parents which are developed according to the self-reports of parents (PMS-P) and adolescents (PMS-A) to assess the parental mediation strategies in Internet usage. Those forms have value of use, they would provide an archive of data collected from parents and adolescents and they will contribute to the practical education programs and researches in the future. The purpose of this study was narrowed down to develop the tools to measure parental mediation strategies. In further research, using the forms of adolescents and parents, the relation between autonomy and parental mediation strategies would be evaluated longitudinally considering the basic criticism that it doesn`t support the autonomy which is a basic variable of adolescence and which is evaluated in control/restrict subdimension of parental mediation strategies. Moreover, it is an important issue to assess whether the mediation strategies provide any change in the quality and quantity of Internet usage or not regarding Turkish culture. At this point, time-lagged panel designs that would discuss Internet usage features and parental mediation strategies together and that would reveal the cause and effect relationship between them might be suggested. This study is limited to a group of adolescents that are in the period of preadolescents and midadolescent and the parents of those adolescents. In future studies, developing the tools to assess the parental mediation strategies for both children and for individuals of pre-adolescent period will provide to assess the mediation strategies for different periods of life regarding that period`s features. What is more, the measurement tools are limited to the adolescents who have an e-mail and a social networking site accounts and their parents. This restriction is originated from the theoretical structure of parental mediation strategies in Internet usage. Nowadays, considering the position of the Internet just for accessing social media or for communication purposes, whether having an account or not will be a variable that will affect the mediation strategies. Therefore, having those accounts are determined as prerequisite for this study. It should also be discussed as a necessary feature to be asked in the personal information form for future studies. 


\section{REFERENCES}

Barkin, S., Ip, E., Richardson, I., Klinepeter, S., Finch, S.\& Krcmar, M. (2006). Parental media mediation styles for children aged 2 to 11 years. Archieves of Pediatrics\& Adolescent Medicine, 160(4), 395-401.

Bayraktar, F. (2017). Çevrimiçi riskler ve ebeveyn aracılık stratejileri: Türkiye'de ve Avrupa'da yaşayan türk kökenli çocuk/ergenlerin karşılaştırılması. Ĕgitim ve Bilim, 42(190), 25-37. DOI: 10.15390/EB.2017.6323

Brown, T. A. (2006). Confirmatory factor analysis for applied research. New York: Guilford Press.

Cabello-Hutt, T., Cabello, P. \& Claro, M. (2017). Online opportunities and risks for children and adolescents: The role of digital skills, age, gender and parental mediation in Brazil. New Media \& Society, 20(7)2411-2431. DOI:10.1177/14614444817724168.

Chang, F. C., Chiu, C. H., Miao, N. F., Chen, P. H., Lee, C. M., Chiang, J. T. \& Pan, Y. C. (2015). The relationship between parental mediation and Internet addiction among adolescents, and the association with cyberbullying and depression. Comprehensive psychiatry, 57, 21-28. DOI: 10.1016/j.comppsych.2014.11.013

Chen, V. H. H. \& Chng, G. S. (2016). Active and restrictive parental mediation over time: Effects on youths' selfregulatory competencies and impulsivity. Computers \& Education, 98, 206-212. DOI: 10.1016/j.compedu.2016.03.012

Clark, L. S. (2011). Parental mediation theory for the digital age. Communication theory, 21(4), $323-343$. DOI:10.1111/j.1468-2885.2011.01391.x

Comrey, A. L., \& Lee, H. B. (2013). A first course in factor analysis. NY: Psychology Press.

Çokluk Ö., Şekercioğlu G.\& Büyüköztürk, Ş. (2014). Sosyal Bilimler için çok değişkenli istatistik SPSS ve LISREL uygulamalarl (3. Bask1). Pegem Akademi, Ankara.

Davies, J. J. \& Gentile, D. A. (2012). Responses to children's media use in families with and without siblings: A family development perspective. Family Relations, 61(3),410-425. DOI:10.1111/j.17413729.2012.00703.x

Diamantopoulos A, Siguaw JA. Introducing LISREL: A Guide For The Uninitiated. London: SAGE; 2000. p.10222.

Elkind, D. (1974). Children and adolescents: Interpretive essays on Jean Piaget. Oxford, Enfland: Oxford U. Press.

Festl, R. \& Langmeyer, A. N. (2018). The Role of Internet Parenting for the Internet use of Children in Pre-, Primary and Secondary School. Praxis der Kinderpsychologie und Kinderpsychiatrie, 67(2), 154-180.

Fikkers, M. K., Piotrowski, T. J.\& Valkenburg, M. P. (2017). A matter of style? Exploring the effects of parental mediation styles on early adolescents media violence exposure and aggression. Computers in Human Behavior, 70, 407-415. DOI: 10.1016/j.chb.2017.01.029.

Fraenkel, R. J. \& Wallen, E. N. (1993). How to design and evaluate Research in Education. New York: McGrowHill.

Gentile, D. A., Nathanson, A. I., Rasmussen, E. E., Reimer, R. A. \& Walsh, D. A. (2012). Do you see what I see? Parent and child reports of parental monitoring of media. Family Relations, 61, 470-487. DOI:10.1111/j.1741-3729.2012.00709.x

Glatz, T., Crowe, E. \& Buchanan, C. M. (2018). Internet-specific parental self-efficacy: Developmental differences and links to Internet-specific mediation. Computers in Human Behavior, 84, 8-17. DOI: 10.1016/j.chb.2018.02.014

Gómez, P., Harris, S. K., Barreiro, C., Isorna, M. \& Rial, A. (2017). Profiles of Internet use and parental involvement, and rates of online risks and problematic Internet use among Spanish adolescents. Computers in Human Behavior, 75(2017), 826-833. DOI: 10.1016/j.chb.2017.06.027

Hastie, T., Tibshirani, R., Sherlock, G., Eisen, M., Brown, P., \& Botsein, D. (1999). Imputing missing values for gene expression arrays. Technical report, Divison of Biostatistics, Stanford University.

Hooper, D., Coughlan, J. ve Mullen, M. R. (2008). Structural equation modelling: guidelines for determining model fit. Electronic Journal of Business Research Methods, 6(1), 53-60.

Hu, L. \& Bentler, P. M. (1999). Cut off criteria for fit indexes in covariance structure analysis: Conventional criteria versus new alternatives. Structural Equation Modeling: A Multidisiplinary Journal, 6(1), 1-55. DOI: 10.1080/10705519909540118.

Kılınç, F. (2017). Çocukların çevrimiçi ortamda karşılaştıkları risk türleri ile aracılık uygulamaları arasındaki ilişki (Master's thesis). Mersin Üniversitesi, Mersin. Retrieved from https://tez.yok.gov.tr/UlusalTezMerkezi

Kirwil, L. (2009). Parental mediation of children's internet use in different European countries. Journal of Children and Media, 3(4), 394-409. DOI: 10.1080/17482790903233440.

Kline, R. B. (2005).Principles and practice of structural equation modelling. N. Y: Guilford Press.

Lee, S. J. (2013). Parental restrictive mediation of children's internet use: Effective for what and for whom?. New Media \& Society, 15(4), 466-481. DOI: 10.1177/1461444812452412. 
Lee, C. \& Kim, O. (2017). Predictors of online game addiction among Korean adolescents. Addiction Research \& Theory, 25(1), 58-66. DOI: 10.1080/16066359.2016.1198474

Lenhart, A., Simon, M. \& Graziano, M. (2001). The Internet and education: Findings of the pew Internet \& American life Project, Washington.

Livingstone, S., Ólafsson, K., Helsper, E. J., Lupiáñez-Villanueva, F., Veltri, G. A. \& Folkvord, F. (2017). Maximizing opportunities and minimizing risks for children online: The role of digital skills in emerging strategies of parental mediation. Journal of Communication, 67(1), 82-105. DOI: 10.1111/jcom.12277

Mares, M. L., Stephenson, L., Martins, N. ve Nathanson, A. I. (2018). A house divided: Parental disparity and conflict over media rules predict children's outcomes. Computers in Human Behavior, 81, 177-188. DOI: 10.1016/j.chb.2017.12.009

Nathanson, A.I. (1999). Identifying and explaining the relationship between parental mediation and children's aggression. Communication Research, 26(2), 124-143.

Nikken, P. \& Schols, M. (2015). How and why parents guide the media use of young children. Journal of Child and Family Studies, 24(11), 3423-3435.

Padilla-Walker, L. M., Coyne, S. M. \& Fraser, A. M. (2012). Getting a high-speed family connection: associations between family media use and family connection. Family Relations, 61(3), 426-440. DOI:10.1111/j.17413729.2012.00710.x

Pasquier, D., Simões, J. A. \& Kredens, E. (2012). Agents ofmediation and sources of safety awareness: Acomparative overview. (Eds. S.Livingstone,L.Haddon ve A.Görzig), Children, risk and safety on the Internet. Bristol, England: Policy Press.

Rideout, V. J., Foehr, U. G. \& Roberts, D. F. (2005). Generation M: Media in the lives of 8-18 year-olds. Henry J. Kaiser Family Foundation.

Sabina, C., Wolak, J. \& Finkelhor, D. (2008). The nature and dynamics of internet pornography exposure for youth. Cyberpsychology and Behavior, 11(6), 691-693. DOI: 10.1089/cpb.2007.0179

Scherer, R. F., Wiebe F. A., Luther, D. C.,\& Adams J. S. (1988). Dimensionality of Coping: Facor Stability Using the Ways of Coping Questionnaire, Psychological Reports, 62(3), 763-770. DOI:10.2466/pr0.1988.62.3.763

Schreiber, J.B., Nora, A., Stage, F.K., Barlow, E.A. \& King, J. (2006). Reporting Structural Equation Modeling and Confirmatory Factor Analysis Results: A Review. The Journal of Educational Research, 99(6), 32338. DOI: $10.3200 /$ JOER.99.6.323-338

Shin, W.\& Huh, J. (2011). Parental mediation of teenagers' video game playing: Antecedents and consequences. New Media \& Society, 13(6), 945-962. DOI: 10.1177/1461444810388025

Shin, W. \& Kang, H. (2016). Adolescents' privacy concerns and information disclosure online: the role of parents and the Internet. Computers in Human Behavior, 54, 114-123. DOI: 10.1016/j.chb.2015.07.062

Sonck, N., Nikken, P. \& de Haan, J. (2013). Determinants of internet mediation. Journal of Children and Media, 7(1), 96-113. DOI: 10.1080/17482798.2012.739806

Spada, M. M. (2014). An overview of problematic Internet use. Addictive Behaviors, 39, 1, 3-6. DOI: 10.1016/j.addbeh.2013.09.007

Steinberg, L. (2007) Ergenlik (Ed. Figen Çok). Ankara: İmge Kitabevi Yayınları.

Sümer, N. (2000). Yapısal eşitlik modelleri: Temel kavramlar ve örnek uygulamalar. Türk Psikoloji Yazıları, 3(6), 49-74.

Sütçü, S. S. (2017). The reactions of the children towards restrictions on their use of informatıon technologies. Journal of Theory and Practice in Education, 13(2), 301-315.

Şencan, H. (2005). Sosyal ve davranışsal ölçümlerde güvenilirlik ve geçerlilik, Hüner Şencan, Ankara.

Tabachnick, B. G., \& Fidel, L. S. (2001). Using multivarite statistics, MA: Allyn ve Bacon.

Thompson, B. (2004). Exploratory and confirmatory factor analysis: Understanding concepts and applications. Washington, DC, US: American Psychological Association.

Treuer, T., Fabian, Z. \& Füredi, J. (2001). Internet addiction associated with features of impulse control disorder: is it a real psychiatric disorder? Journal of Affective Disorders, 66(2-3), 283.

TÜİK (Türkiye İstatistik Kurumu) (2017). Hane Halkı Bilişim Teknolojileri Kullanım Araştırması. http://www.tuik.gov.tr/PreTablo.do?alt_id=1028 İnternet adresinden 28.08.2017 tarihinde edinilmiştir.

Valkenburg, P.M., Krcmar, M., Peeters, A.L. \& Marseille, N. M. (1999). Developing a scale to assess three styles of television mediation: "Instructive mediation," "restrictive mediation," and "social coviewing. Journal of Broadcasting \& Electronic Media, 43(1),52-66.

Valkenburg, P. M., Piotrowski, J., Hermanns, J., \& de Leeuw, R. (2013). Developing and validating the Perceived Parental Media Mediation Scale: a self- determination perspective. Human Communication Research, 39(4), 445-469. DOI: 10.1111/hcre.12010 
Vaterlaus, J. M., Beckert, T. E., Tulane, S. \& Bird, C. V. (2014). "They always ask what I'm doing and who I'm talking to": Parental mediation of adolescent interactive technology use. Marriage \& Family Review, 50(8), 691-713. DOI: 10.1080/01494929.2014.938795

Wang, R., Bianchi, S. M. \& Raley, S. B. (2005). Teenagers' Internet use and family rules: A research note. Journal of Marriage and Family, 67(5), 1249-1258. DOI: 10.1111/j.1741-3737.2005.00214.x

Warren, R. (2001). In words and deeds: Parental involvement and mediation of children's television viewing. Journal of Family Communication, 1(4), 211-231. DOI: 10.1207/S15327698JFC0104_01

Widyanto, L. \& McMurran, M. (2004). The psychometric properties of the internet addiction test. Cyberpsychology \& Behavior, 7(4), 443-450. DOI: 10.1089/cpb.2004.7.443

Williams, A. L. \& Merten, M. J. (2011). iFamily: Internet and social media technology in the family context. Family and Consumer Sciences Research Journal, 40(2), 150-170. DOI: 10.1111/j.15523934.2011.02101.x 